\title{
ANALISIS KELAYAKAN FINANSIAL USAHA PEMBUATAN TEMPE KEDELAI SKALA MIKRO DI KECAMATAN SEMARANG BARAT
}

\author{
GALIH SETO WICAKSONO') ${ }^{1)}$, TINJUNG MARY PRIHTANTI ${ }^{2)}$
}

\author{
1,2) Agribisnis; Universitas Kristen Satya Wacana \\ Email : (gilbertusgalih@gmail.com)
}

\begin{abstract}
This study aims to analyze the feasibility of the financial business of making micro-scale tempeh in Semarang Barat Sub-district in 2018. This research is a quantitative study using a survey method with 30 respondents with criteria as experts in business tempeh agrondustry in Semarang Barat Subdistrict. Investment feasibility analysis uses Net Present Value (NPV) analysis, Internal Rate of Return (IRR) and R / C Ratio analysis to find out whether there is a business tempeh agroindustry in Semarang Barat Sub-district that is feasible or not. The results of the feasibility analysis of tempe making business for 3 years, the business tempeh agroindustry is feasible to be developed, this is based on the results of research that shows the $N P V(+)$ value of $R p .61,730,980$ which shows that the industry is feasible for investment. While the IRR (65.8\%)> interest rates on commercial bank loans $(D F=11 \%)$ indicate that the business of making tempe is feasible for investment. And the value of $R / C$ ratio (1.156) $>1$, which means that the business tempeh agroindustry in Semarang Barat sub-district is feasible.
\end{abstract}

Keywords : Agroindutsry, Financial feasibility, Tempeh

\section{PENDAHULUAN}

Strategi pembangunan ekonomi bangsa Indonesia yang kurang pada masa lalu dan juga krisis ekonomi yang berkepanjangan, menimbulkan berbagai persoalan ekonomi bagi bangsa Indonesia. Salah satu solusi untuk megatasi masalah ekonomi yang begitu kompleks diperlukan strategi pembangunan ekonomi yang mampu memberikan solusi bagi bangsa Indonesia untuk menuju perekonomian yang lebih baik dan cerah.

Di antara pilihan strategi pembangunan ekonomi yang ada, strategi pembangunan yang memenuhi karakteristik tersebut adalah Pembangunan Agribisnis (agribusiness development) yaitu strategi pembangunan ekonomi yang mengintegrasikan pembangunan pertanian berkelanjutan (perkebunan, peternakan, perikanan, dan kehutanan) dengan pembangunan industri hulu dan juga industri hilir sektor pertanian serta sektor-sektor jasa yang terkait di dalamnya (Saragih, B. 1998).

Pengembangan agroindustri dengan skala UMKM (usaha mikro kecil menengah) dapat menjadi salah satu solusi untuk meningkatkan perekonomia masyarakat. Industri tempe skala mikro yang ada di masyarakat ini merupakan salah satu industri yang cukup potensial untuk dikembangkan secara lebih jauh. Tempe merupakan salah satu makanan yang memiliki nilai gizi tinggi namun dengan harga yang cukup rendah, sehingga menjadi primadona bagi sebagian masyarakat Indonesia. 
Kecamatan Semarang Barat merupakan salah satu sentra pembuatan tempe yang ada di Kota Semarang, terutama berpusat di Kelurahan Krobokan. Sentra industri pengolahan ini merupakan pemasok tempe-tempe kedelai di pasar-pasar tradisional yang ada di Kota Semarang. Namun, fenomena yang sedang terjadi di pasar adalah turunnya daya beli masyarakat terhadap produk-produk yang di jual di pasar, salah satu produk tersebut adalah tempe kedelai. Sehingga perlu adanya kajian akan kelayakan finansial usaha pembuatan tempe kedelai untuk menentukan apakah usaha ini memang layak untuk terus dilanjutkan beroprasi atau tidak, ditilik dari penghitungan biaya dan manfaat yang diharapkan, dengan membandingkan antara pengeluaran dan pemasukan usaha, seperti halnya ketersediaan dana, biaya modal, kemampuan untuk membayar kembali dana tersebut dalam waktu yangtelah ditentukan dan menilai apakah proyek dapat terus berkembang (Umar, 2003).

\section{METODE PENELITIAN}

Penelitian ini dilaksankan pada bulan Juli 2018 hingga Agustus 2018, dengan lokasi penelitian bertempat di Kecamatan Semarang Barat, Kota Semarang. Jenis penelitian yang digunakan adalah penelitian kualitatif menggunakan metode survei. Jenis dan sumber data yang digunakan merupakan data primer dan data sekunder, dimana dapat primer berasal dari wawancara langsung dengan responden dan data sekunder berasal dari studi literatur, penelitian-penelitian terdahulu dan pustaka lain yang terkait dengan penelitian. Penelitian ini menggunakan 30 orang responden, respoden yang dipilih memiliki kriteria sebagai pelaku usaha pembuatan tempe kedelai yang berada di Kecamatan Semarang Barat.

Analisis data dilaksanakan secara deskriptif yang berguna untuk menggambarkan variable yang sedang diteliti (Arikunto, 2006). Data yang telah terkumpul di analisis menggunakan analisis kriteria investasi (NPV, IRR) ditambah dengan analisi R/C Ratio untuk mengetahui apakah usaha pembuatan tempe di Kecamatan Semarang Barat ini layak untuk diusahakan atau tidak. Dimana :

a. Net Presnt Value (NPV)

Pengukuran NPV $=\sum_{t=1}^{n} \frac{C F_{t}}{(1+i)} t-C o$

Keterangan: $\quad \mathrm{CF}_{\mathrm{t}}=$ Aliran kas per tahun pada periode $\mathrm{t}$

$\mathrm{C}_{\mathrm{o}} \quad=$ Investasi awal pada tahun ke-0

$\mathrm{n} \quad=$ Jumlah tahun

$\mathrm{i} \quad=$ Tingkat suku bunga

$\mathrm{t} \quad=$ Tahun ke-

Kriteria yang digunakan :

1. NPV $>1$, Maka usaha tersebut layak.

2. $\mathrm{NPV}=0$, Maka usaha tersebut dapat layak.

3. NPV $<1$, Maka usaha tersebut tidak layak (Umar, 2003). 
b. Internal Rate of Return (IRR)

$$
\begin{aligned}
\text { Pengukuran IRR }=\mathrm{i}_{1}+\frac{\mathrm{NPV}_{1}}{N P V_{1}-N P V_{2}}\left(i_{2}-i_{1}\right) \\
\text { Keterangan: } \\
\mathrm{NPV}_{1}=\text { Nilai NPV 1 } \\
\mathrm{NPV}_{2}=\text { Nilai NPV 2 } \\
\mathrm{i}_{1}=\text { Tingkat suku bunga } 1 \\
\mathrm{i}_{2}=\text { Tingkat suku bunga } 2
\end{aligned}
$$

Kriteria yang digunakan :

1. Jika IRR > suku bunga pinjaman maka proyek dikatakan layak.

2. IRR $<$ suku bunga pinjaman dikatakan bahwa proyek tidak layak.

c. R/C Ratio

Pengukuran $\mathrm{R} / \mathrm{C}$ Ratio $=\frac{\text { Penerimaan }}{\text { Total Biaya (biaya tetap }+ \text { biaya variabel })}$

Kriteria yang digunakan :

1. Jika $\mathrm{R} / \mathrm{C}>1$, maka usaha akan dinyatakan untung dan layak untuk diusahakan. diusahakan.

Jika $\mathrm{R} / \mathrm{C}<1$, maka usaha dinyatakan merugi dan tidak layak untuk

\section{HASIL DAN PEMBAHASAN}

1. Penilaian Kelayakan Investasi Usaha

Kriteria yang digunakan untuk pengambilan keputusan penilaian investasi usaha adalah: Net Present Value (NPV), Internal Rate of Return (IRR) dan $\mathrm{R} / \mathrm{CRatio}$ sebagai tambahan untuk mengetahui apakah usaha layak atau tidak untuk dijalankan. Hasil pengolahan data dapat dilihat pada Tabel 1.

Tabel 1. Hasil Analisis Kelayakan Finansial usaha Pembuatan Tempe Kecamatan Semarang Barat Tahun 2018-2020

\begin{tabular}{lr}
\hline Kriteria Investasi & Nilai \\
\hline NPV & Rp. 61.730 .980 \\
IRR & $65.8 \%$ \\
R/C Ratio & 1.156 \\
Rata-rata NPV pertahun & Rp. 20.576 .993 \\
Rata-rata NPV perbulan & Rp. 1.714 .749 \\
\hline
\end{tabular}

a. $\quad$ Net Present Value (NPV)

Net Present Value merupakan selisih antara Present Value dari investasi dan nilai sekarang dari penerimaan - penerimaan kas bersih di masa yang akan datang (Umar, 2003). Berdasarkan tabel 1 dapat dilihat bahwa dengan Discount Factor (DF) sebesar 11\% usaha pembuatan tempe menghasilkan NPV sebesar Rp. 61.730.980, yang berarti bahwa dalam 3 tahun dengan singkat suku bunga $11 \%$ usaha pembuatan tempe menghasilkan keuntungan sebesar Rp. 61.730.980, dengan rata-rata keuntungan pertahun sebesar Rp. 20.576. 993, keuntungan perbulan sebesar Rp. 1.714.749. Dengan hasil NPV yang positif menunjukan bahwa industri pembuatan tempe di Kecamatan Semarang Barat secara finansial layak untuk dilakukan investasi usaha. Hasil ini sejalan dengan penelitian yang dilaksankan oleh Oktaviyani (2016) yang 
menyatakan bahwa nilai NPV dari 5 tahun usaha pembuatan tempe Bapak Yana menghasilkan NPV sebesar Rp. 44.350.600.

b. Internal Rate of Return

Internal Rate of Return merupakan tingkat discount factor (DF) yang menghasilkan NPV sama dengan nol. Besaran yang dihasilkan dari perhitungan ini adalah dalam satuan persentase (\%) (Nurmalina, 2009). Dari tabel 1 diketahui bahwa hasil perhitungan menunjukan bahwa nilai IRR yang didapat sebesar $65,8 \%$ yang mana nilai IRR(65,8\%) lebih besar dari tingkat suku bunga pada bank umum (11\%), artinya tingkat pengembalian usaha pembuatan tempe di Kecamatan Semarang Barat ini layak untuk dilaksanakan. Hasil penelitian ini sejalan dengan penelitian yang dilakukan oleh Oktaviyani (2016) yang hasil penelitiannya menyatakan bahwa nilai IRR yang didapatkan sebesar 33,86\% pertahun, atau lebih besar dari tingkat suku bunga bank sebesar $12 \%$

c. R/C Ratio

$\mathrm{R} / \mathrm{C}$ Ratio dimaksudkan untuk mengetahui keuntungan relatif yang nantinya akan diperoleh pada sebuah proyek atau sebuah usaha. Proyek dinyatakan layak bila nilai $\mathrm{R} / \mathrm{C}$ yang dihasilkan lebih besar daripada 1. Dari tabel 1 diketahui bahwa usaha pembuatan tempe di Kecamatan Semarang Barat memiliki nilai R/C Ratio $(1,156)>1$, yang berarti bahwa setiap Rp. 1000 biaya yang dikeluarkan oleh pengusaha tempe akan mendapatkan penerimaan sebesar Rp. 1.156 dan pendapatan sebesar Rp. 0,156 yang membuktikan bahwa usaha pembuatan tempe kedelai di Kecamatan Semarang Barat ini layak untuk di usahakan. Hasil ini juga sejalan dengan penelitian yang dilakukan oleh Sunarti (2017) yang menyatakan bahwa rata-rata agroindustri di Desa Pananjung sebesar 1,21. Dimana nilai R/C yang diperoleh lebih besar daripada 1, maka dapat disimpulkan bahwa Agroindustri di Desa Pananjung layak diusahakan dan menguntungkan.

\section{KESIMPULAN DAN SARAN}

\section{Kesimpulan}

Berdasarkan hasil penelitian, kesimpulan yang diperoleh adalah :

1. Hasil penelitian analisis kelayakan finansial dengan tingkat suku bunga sebesar 11\% dengan jangka waktu usaha sepanjang 3 tahun menunjukan bahwa Usaha Pembuatan Tempe pada Kecamatan Smearang Barat layak untuk dikembangkan untuk kedepannya. Hal ini didasari oleh perhitungan nilai Net Present Value (NPV) > 0, dengan nilai NPV sebesar 61.730.980, dan nilai Internal Rate of Return (IRR) sebesar 65,8\% yang mana lebih besar dari tingkat suku bunga (11\%), sedangkan nilai R/C Ratio menunjukan nilai sebesar 1,156 atau R/C Ratio > 1, sehingga usaha pembutan tempe ini layak untuk diusahakan.

\section{Saran}

Berdasarkan hasil kesimpulan yang ada, saran yang dapat penulis berikan adalah untuk membentuk kembali PRIMKOPTI (Primer Koperasi Produsen Tempe Tahu Indonesia) yang sebelumnya pernah dibangun oleh Dinas Koperasi dan UMKM Kota Semarang. Hal ini dikarenakan fungsi dari PRIMKOPTI yang mana untuk mengembangkan potensi dan kemampuan ekonomi anggota untuk dapat meningkatkan kesejahteraan ekonomi dan sosial. PRIMKOPTI juga dapat 
menjadi sebuah wadah antara pengrajin dan juga pemerintah kota, dimana pemerintah dapat memberikan penyuluhan-penyuluhan yang sekiranya dapat membantu pengrajin untuk meningkatkan kapasitas produksi dan juga bisa sebagai penyalur bantuan-bantuan dari pemerintah yang terkait akan usaha pembuatan tempe seperti peminjaman modal usaha, kedelai bersubsidi atau bantuan alat pengolahan tempe kedelai, agar bantuan yang diberikan oleh pemerintah dapat tepat sasaran dan benar-benar membantu pengrajin tempe untuk memiliki perekonomian yang lebih baik lagi.

\section{DAFTAR PUSTAKA}

Arikunto, Suharsimi. (2006). Prosedur Penelitian Suatu pendekatan Praktek. Jakarta: Rineka Cipta.

Nurmalina R, Sarianti T, Karyadi A. (2009). Studi Kelayakan Bisnis. Bogor: Dapartemen Agribisnis, fakultas Ekonomi dan Manajemen, IPB.

Oktaviyani, H., Soetoro, \& Pardani, C. (2016). ANALISIS KELAYAKAN FINANSIAL PADA AGROINDUSTRI TEMPE (Studi Kasus pada Pengrajin Tempe di Kelurahan Banjar Kacamatan Banjar Kota Banjar). Jurnal Ilmiah Mahasiswa AGROINFO GALUH, 2 (3), 181-188.

Sarangih, B. (1998). Agribisnis, Paradigma Baru Pembangunan Ekonomi Berbasis Pertanian (Kumpulan Pemikiran). Bogor: Yayasan Persada Mulia Indonesia.

Sunarti, Sujaya, D.,H., Hardiyanto, T. (2017). ANALISIS BIAYA, PENDAPATAN DAN R/C AGROINDUSTRI TEMPE (Studi Kasus pada Pengrajin Tempe di Desa Pananjung Kecamatan Pangandaran Kabupaten Pangandaran). Jurnal Ilmiah Mahasiswa AGROINFO GALUH, 4 (3), 376381.

Umar, Husein. (2003). Studi Kelayakan Bisnis: Teknik Menganalisis Kelayakan Rencana Bisnis secara Komprehesif. Ed ke-2. Jakarta: Gramedia Pustaka Utama 